\title{
Inequality of Opportunity in The Labor Market: Evidence from Sudan
}

\author{
Huda Mohamed Mukhtar Ahmed \\ University of Khartoum, Khartoum, Sudan \\ E-mail: haudashalaby@gmail.com, haudashalaby@uofk.edu
}

Eiman Adil Mohamed Osman

University of Khartoum, Khartoum, Sudan

E-mail: eimanjoda@gmail.com, eiman.osman@uofk.edu

Hatim Ameer Mahran

Al-Imam Muhammad Ibn Saud Islamic University, Saudi Arabia

E-mail: mahranec@yahoo.com, hamuhran@imamu.edu.sa

Received: April 13, 2020 Accepted: May 8, 2020 Published: May 10, 2020

doi:10.5296/jsss.v7i2.16833 URL: https://doi.org/10.5296/jsss.v7i2.16833

\begin{abstract}
This paper examines the inequality of opportunity in the labor market in Sudan, using data of the Poverty Survey, 2014. A logit model is used with the dependent variable taking 1 if the person is employed and 0 otherwise. A set of circumstance variables are used as regressors, and ex-ante inequality of opportunity is calculated using the dissimilarity index and Shapley decomposition. Gender was associated with the largest share of inequality of opportunity, estimated at 73.41 percent. Gender-based inequality of opportunity in employment was assessed using Blinder-Oaxaca decomposition methods. The findings reveal that the average probability of accessing employment is 0.87 for men and 0.59 for women, yielding a gap of 0.274. The difference between the average group characteristics of males and females was reflected in the coefficient of endowment (0.008), representing 2.9 percent of the total difference. The bulk of the gap is attributed to differences in circumstances, as indicated by the difference of 0.249 in the coefficients, representing 90.8 percent of the total difference.
\end{abstract}


This difference is interpreted as discrimination. The results call for substantial reforms, not only in the labor market but, more importantly, with regard to circumstance variables over which the individuals have no control.

Keywords: Inequality of opportunity, Shapley Decomposition, Blinder-Oaxaca Decomposition, Employment, Sudan

\section{Introduction}

The debate on the relationship between inequality and growth attracted the attention of economists and social scientists a long time ago. Classical economists believe there is a positive correlation (not causation) between inequality and growth, at least over the short term (Lewis 1954; Kuznets 1955). While some argue that inequality is not a prerequisite of economic growth (Kuznets, 1955), others contend that inequality is important for growth. The marginal propensity to expend is lower for the rich compared to the poor so that a skewed income distribution leads to higher savings, more investment, and higher growth. The 1980s and 1990s witnessed the adoption of stringent adjustment policies, which have led to political instability and social unrest associated with heavy taxes and inequality. This has led some authors to link inequality with political instability. Under such circumstances, it is natural for investment and growth to slow down, suggesting a negative relationship between inequality and growth (Alesina\& Rodrik 1994).

However, income inequality has many sources. A distinction has been made between inequality arising from factors that are beyond the individual responsibility, and inequality due to personal responsibility. Roemer (1998) offered an influential formalization of the concept of equality of opportunity. For this purpose, he separated the determinants of a person's desirable outcomes (advantages) such as employment into two distinct sets of factors. The first set, called circumstances, includes factors that are economically exogenous to the person, such as gender, race, mode of living, place of birth, and family background. These factors may affect an individual's employment opportunity but cannot be influenced by the individual. The second set, called effort, includes factors that can be influenced by the individual's choice. According to Roemer (1998), to adopt an equal opportunity policy, the population should first be partitioned into homogeneous-circumstance groups (types), where every individual share exactly the same set of circumstances. This suggests that the population should be partitioned such that the distribution of outcomes becomes dependent on effort and independent of circumstances. In this case, an equal-opportunity policy is the one that equalizes "advantages" for each centile of the effort distribution across individual groups (types).

Following the work of Roemer, several methodologies have been developed with many empirical applications to assess inequality in opportunity. Indeed, over the last two decades, the concept has been applied in different domains of public policy, including those related to wealth and income distribution, poverty reduction, educational attainment, health and access to health care, and access to labor markets. The most related study for Sudan assessed the gender gap in education and related returns. The findings revealed that as a consequence of the gender gap in education, women are more likely to be unemployed compared to men (Nour , 2011). Sudanese societies have multi-ethnic groups, and inequality of opportunity is 
more noticeable in such societies. Inequality of opportunity in employment and the related exclusions generate a sense of injustices and leads to political instability. Examining such inequalities may help in eliminating some of the causes of the prolonged economic and political problems in Sudan. However, few studies are available in Sudanese labor market literature.

Based on the work of Roemer (1998), this attempts to examine inequality of opportunity in accessing the labor market in Sudan, using more recent data from the National Household Budget and Poverty Survey (NHBPS) conducted by the Central Bureau of Statistics in 2014. The paper examines the relationship between access to the labor market and a set of circumstance variables. It then measures the in-labor market inequality of opportunity and assesses the contribution of each circumstance variable in total inequality. This paper believes that such inequality may give rise to considerable waste in human capital, which more likely will impact negatively on development and growth potentials.

It is observed that gender is associated with the largest share of inequality of opportunity. Differentials in inequality of opportunity in employment between males and females were assessed using Shapley and Blinder-Oaxaca decomposition methods. The findings reveal that the average probability of accessing employment is 0.91 for men and 0.60 for women, yielding a gap of 0.31 . The sources of this gap were examined. Little difference is observed between the average group characteristics of males and females, with females having slightly better characteristics (endowment), which represents 2.9 percent of the total gap. The bulk of the gap in opportunity is attributed to differences in circumstances, representing 90.8 percent of the total difference. It is hoped that these findings provide some guidance for policymakers in designing evidence-based policies.

The remaining part of the paper is organized as follows: level 1.1 outlines some salient features of the Sudanese labor market; level 1.2 briefly reviews the literature, while section 2 outlines the research methodology and section 3 discusses the results; section 4 concludes with some remarks.

\subsection{Salient Features of the Labor Market in Sudan}

The Sudanese economy has been characterized by the dominance of the public sector in economic activity, reflecting the large share of that sector in total employment compared to the private sector. During the 1980s, the Sudanese labor market was characterized by considerable regional mobility with little intervention in the workings of the private labor market (Fallon, 1987). Thus, there was a competitive labor market for the private sector despite the extensive government intervention in the economy and the growing surplus of specific categories of workers.

The organizational structure of the labor market is characterized by weak regulations and inefficient institutional settings, rigidity, and lack of dynamism, deficiency in monitoring, planning and skill upgrading, and the high incidence of duality (rural-urban; traditional-modern and formal-informal sectors). In addition to persistent government intervention in economic activity, these features coincided with high growth rates of the population and the labor force, together with macroeconomic fluctuations.

During the 1990s, the government introduced economic reforms and adopted economic 
liberalization measures to encourage private sector participation in economic activity. In 1999 Sudan began to export oil. Since then, the economy has become increasingly dependent on oil exports to the extent that Sudan has moved from having a low-income economy into a lower medium-income economy according to World Bank classification. Though the civil war in the South, Blue Nile, and Darfur have had adverse effects on investments and labor market, the exploration of oil led to job creation, but also to influxes of labor migrants from Asia and neighboring countries, with the majority engaged in the private sector. These developments were arrested by economic sanctions and, in most recent times, the loss of oil as a source of foreign exchange earnings following the secession of South Sudan.

Two main sectors constitute the major sources of wage employment in rural areas, namely the large state-owned and managed irrigation schemes in the northern regions, and the large mechanized farms in the rain-fed eastern regions. The slowdown in labor absorption combined with large influxes from rural to urban areas has exerted more pressure on the labor market, especially in urban areas. The most striking feature of the rural labor market in Sudan was the sheer scale of seasonal labor migration (Fallon, 1987).

The labor force in Sudan amounted to 5.48 million people in 1990, increasing to 11.73 million people in 2018, with an annual growth rate of 3.93 percent during the period. Females represent only one-quarter of the labor force. For the present paper, we examine the trends of two indicators of the labor market, namely the rate of unemployment and the labor force participation rate.

Figure (1) below depicts the trends in the unemployment rate for Sudan according to gender during 1990-2018. The difficulties facing the labor market were reflected in the prevalence of high rates of unemployment, estimated at an average of 15.0 during the period, with a maximum rate of 16.9 percent registered in 2000. The unemployment rate is the highest for the youth, estimated at an average of 29.7 percent during the period, and with a maximum rate of 32.7 percent registered in the year 2000. This is attributed mainly to the unprecedented expansion in higher education and the mismatch between educational output and labor market requirements, and also to youth bulge resulting from the demographic transition. The rates for males and females averaged 12.6 percent and 22.2 percent, respectively, with maximum rates of 15.1 in 2000 for males and 24.64 in 2010 for females. These figures indicate the relatively large difference between the rates for males and females against the latter. Indeed, Fig (1) suggests that although the overall rate has fallen, the rate for females has exhibited an upward trend since 2009, while the rates for males and the youth have fallen following the overall trend.

The labor participation rate is another important labor market indicator, (defined by the US Bureau of Labor Market Statistics): as the proportion of the population aged 15 and above that is economically active (all people supplying labor for the production of goods and services during a specified period). Figure (2) depicts the trend of this rate for males and females during 1990-2018.

The difficulties facing the labor market were once more reflected in the prevalence of low rates of labor participation, with an average rate of 49.2 during the period, and a maximum rate of 51.7 percent registered in 1996. The participation rate is considerably high for males, estimated at an average of 73.7 percent during the period, and with a maximum rate of 76.6 
percent registered in the year 1990. The rate for females averaged 25.0 percent, with a maximum rate of 28.5 in 1996 . These figures indicate the considerable difference between the rates for males and females against the latter. Indeed, Fig (2) suggests that although the rate for all groups has fallen, the fall in the rate for females has been noticeable since 1996.

These features of the labor market were also reflected in the latest National Baseline Household Budget Survey (NBHBS) conducted by the Central Bureau of Statistics in 2014/15. The findings of the survey suggest that the labor force participation rate for Sudan is lower than the average for Sub-Saharan African countries and lower-middle-income countries. Nearly half of the urban population participates in the labor force, compared to 56 percent for the rural population. Moreover, every 3 in 4 males are labor force participants, compared to only 1 in 3 for females. Poorer quintiles' populations and those with no qualifications have higher participation rates. These two groups are most probably engaged in low-skill work. The employed population was mainly from rural areas, males, and those with no qualifications. While the unemployed were mainly from urban areas, females, and those with higher educational attainments, more than half were from richer quintiles.

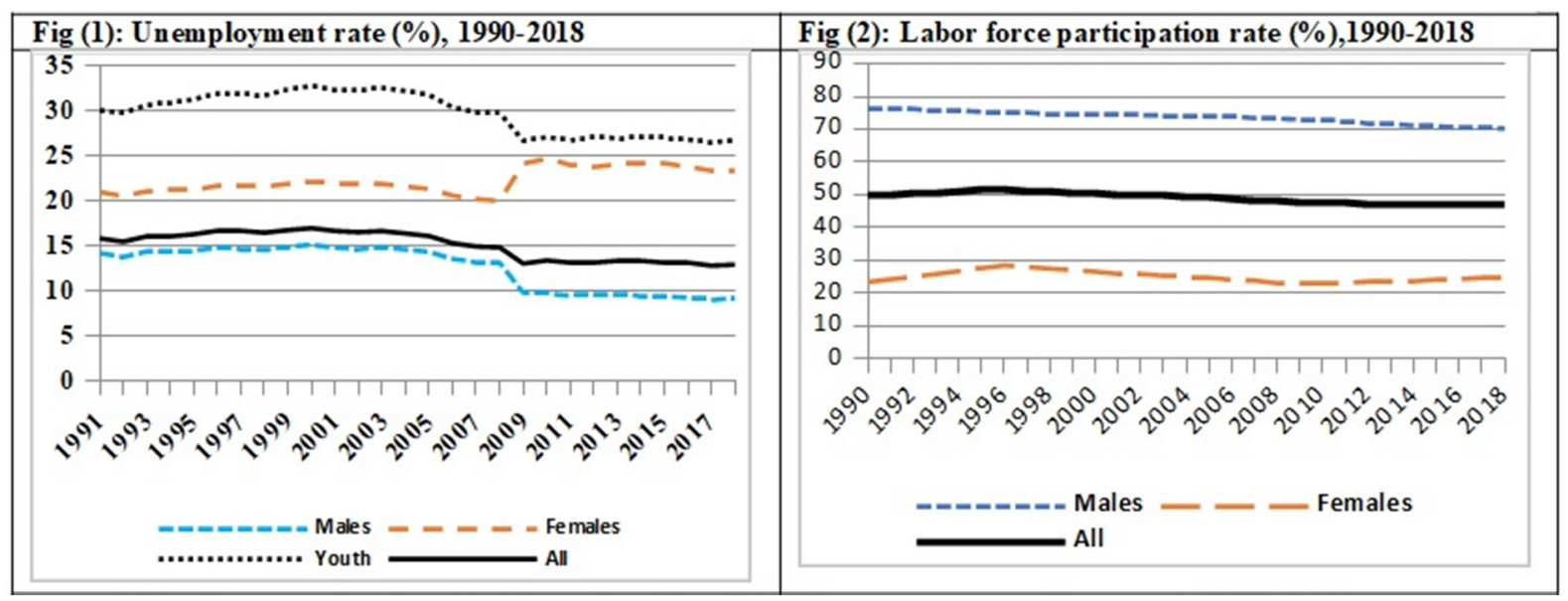

Source: Authors' construction based on data from the Global Economy accessed at www. The GlobalEconomy.com

Figure 1. Unemployment rate (\%), 1990-2018
Figure 2. Labor force participation rate (\%), $1990-2018$

In light of these features, the present paper addresses the question of whether the labor market in Sudan discriminates between males and females with regard to the opportunities available for both sexes in that market and, if so, what are the most important determinants of such inequality. The paper is based on the new concept of inequality of opportunity introduced by Dworkin (1981), Arneson (1989), and Cohen (1989), and operationalized by Roemer (1993 and1998) ( as cited in Roemer and Trannoy,2016),. Instead of blaming inequality on factors that individuals can control, the new approach emphasizes factors beyond the control of the individuals.

\subsection{Literature Review}

The debate on the kind of equality that communities aim at has continued since the last 
century. Despite common consensus among them, many scientists and political philosophers explained equality of opportunity from a different point of view. The common belief is that individuals must have the freedom to attain what they desire without being restricted by factors or circumstances beyond their control (Rawls, 1971; Sen, 1980; Dworkin, 1981; Arneson, 1989; Cohen, 1989; Roemer, 1998).

Most of the literature has concentrated on income inequality, which is a result of socio-economic and demographic changes that generate income distribution. Recently, Dworkin (1981) and Roemer (1998) argued for new concepts that have put personal responsibility as a priority of the debate on equality. Based on this concept, the new debate calls for economic and social policies that promote equality of opportunity (Lefranc et al., 2008), and for compensating inequality stemming from factors beyond the control of the individual while letting individuals be responsible for inequality stemming from factors they can control.

Recently, Roemer et al.(2003), and Roemer 1998) crystallized the concept of inequality of opportunity and called the factors under the individual's control as "efforts" (including years of schooling, training, or being hard worker), and called the ones over which individuals have no control as "circumstances" such as race, gender, or family background. Based on this definition, Roemer (1998) defined equality of opportunity as a situation in which the outcomes achieved (defined as "advantages") are independent of the circumstance variables.

The pioneering work by Roemer (1998) and Van De Gaer (1995,cited by Ferreiraetal.,2014) for examining inequality of opportunity focuses on how societies should compensate individuals for differences in outcome due to factors beyond their control. The theoretical work of Roemer (1998) and Van de Gaer (1995), together with the contribution by Fleurbaey (1994) and Bossert (1995), have led to two fundamental ethical principles upon which the concept of equality of opportunity rests, namely the principle of compensation and the principle of reward. The first principle requires removing the inequalities due to circumstances, while the second principle determines how to compensate efforts for individuals sharing the same circumstances.

Inequalities based on "circumstances" and "efforts" affect economic growth differently. While the inequality based on circumstances may reduce growth as it favors human capital accumulation by individuals with better social circumstances, and not with better ability or skills; the inequality that is based on exerted efforts can boost growth since it may encourage people to invest in education and training (Marrero \& Rodríguez, 2013)

In a well-functioning labor market, the outcomes differ across individuals depending on the quality of their education level, the skills attained by training, as well as the work effort they exert. Likewise, if the education system is functioning well, the human capital and skills that individuals accumulate should reflect differences in the effort they exerted in school (Krafft, \&Assaad, 2016). Differences in human capital must account for the disparities in labor. Sometimes, however, some circumstance variables determine participation in the labor market. Identifying the source of inequality of opportunity on the bases of "circumstances" and "efforts" will enhance our understanding of the exact relationship between inequality and growth. 
Abraset al., 2013 used the Human Opportunity Index (HOI) methodology and data from the 2006 Life in Transition Survey to quantify inequality of opportunity in labor market outcomes in Europe and Central Asia. The authors compared HOI-based measures of inequality with expenditure-based measures. They also examined the extent to which these measures resonate with perceptions of life satisfaction and fairness. Their findings revealed substantial inequality of opportunity in employment status across countries. Correlations between measures and perceptions of inequality suggest that inequality between groups, as opposed to overall inequality, is strongly associated with perceptions of fairness in society.

Nyokangi (2014) applied two distinct indices of inequality of opportunity to examine the impact of circumstances on the inequality of opportunity in the South African labor market. The opportunities needed to reallocate all economically active South Africans to have equal access to employment, irrespective of their circumstances, were estimated. The empirical findings showed that the circumstance variables such as race, gender, and parental education had an insignificant effect on inequalities in accessing employment, whereas the same variables have a considerable impact on income inequalities.

Krafft and Assaad (2016) investigated in-market inequality of opportunity in Egypt and Jordan, focusing on the experiences of higher education graduates in the labor market. The study examined the effect of some circumstances on access to the labor market, such as gender, place of birth, and family background, after carefully controlling for the type and quality of human capital that an individual possesses. The findings showed that substantial in-market inequality exists in both countries, but so more in Egypt, indicating that the functioning of the labor market itself is a significant source of inequality of opportunity.

A study in Nigeria investigated gender inequality in employment, specifically decent employment. To ascertain the gravity of inequality, the problem was examined at the national level, as well as for the political and academic sectors. A survey was conducted covering six universities as well as results from the three elections during 2003-2011. The findings revealed that women are marginalized in many decent works, being limited to trading and farming in the informal sector. The factors responsible for such inequality include the educational strategy of the country, legacy of the colonial period, and the patriarchal nature of the country as well as the types of jobs, some of which are identified with women (Oloni, 2015).

To our knowledge, inequality of opportunity in the labor market is not discussed in the literature on Sudan. Few studies addressed the gender gap in education and its related implications for the labor market and return to education using micro-level survey data. Nour (2011), for example, focused on the determinants of the gender gap and the differences in returns to education, including the wage rate, education level, experience, and its square. Despite the slight difference in the rate of returns to education between males and females, estimated at only 0.2 against women, the author called for enhancing educational attainment for women to improve returns to their education. Since women are likely to be more unemployed than men, improving their educational level also enhances their accession to the labor market. 


\section{Research Methodology}

Inequality of opportunity, as a concept, has received an increasing attention in development economics over the last two decades. In his influential contribution, Roemer (1998) attributed total inequality to differences in two sets of factors: a set of variables related to an individual's circumstances $(C)$ and a set of variables related to an individual's effort $(E)$. The first set includes socio-demographic attributes like gender, race, mode of living, place of residence, parental education, and other family backgrounds, while the second set corresponds substantially to the individual's activities towards improving skills and income, including years of formal schooling and job training. According to Roemer (1998), the individual has no control over the set of circumstances variables, while he can control the set of effort variables. Both sets of variables give rise to inequality of opportunity. However, the individual should not be held responsible for inequality arising from his circumstances. These are factors that people cannot change, but at the same time, affect their outcome. The part of inequality due to different levels of effort is the ethically non-offensive inequality. In contrast, the ethically offensive part of inequality is the part that is due to circumstances beyond the control of individuals Checchi and Peragine (2010)

This paper examines the inequality of opportunity to participate in the labor market in Sudan. Accessing employment represents the outcome of our interest. Following Roemer (1998), this outcome, denoted $\left(W_{i}\right)$, is determined by circumstances $\left(C_{i}\right)$ and efforts $\left(E_{i}\right)$. This relationship may be written in the following general functional form:

$$
W_{i}=f\left(C_{i}, E_{i}\right)
$$

To assess inequality of opportunity, Fleurbaey and Peragine (2013) distinguished between ex-ante and ex-post inequality of opportunity. Ex-ante equality of opportunity is realized when circumstances do not affect the outcome. The ex-post approach focuses more on effort so that equality of opportunity is realized if all people making the same effort achieve the same outcome regardless of their circumstances.

Empirically, the ex-ante approach is much easier to implement than the ex-post approach. The main challenge for both approaches is that effort is not observable. We cannot estimate the ex-post approach without at least one effort variable while the ex-ante approach can be estimated without any (Florian \& Isidro, 2014). This is probably the main reason why empirical applications focus mostly on ex-ante inequality of opportunity. This paper follows the empirical applications, proposed in the previous studies, and focuses on ex-ante inequality of opportunity.

Several methods have been proposed to obtain ex-ante point estimates of inequality of opportunity for both continuous and dichotomous variables. The regression approach became very popular, whereby the outcome (employment) is related to circumstances by parametric or nonparametric regression methods. This approach is more focused on inequalities between social groups defined by the same set of circumstances. For this reason, the population is partitioned into $k$ different types sharing the same circumstances. In this case, the ex-ante approach estimates inequality of opportunity as inequality between groups or 'types' that share the same circumstances. Following the previous studies, we suppressed "within-group" differences by examining whether the conditional distributions of $W_{i}$ differ across types. Thus, 
with the assumption that the outcome $W_{i}$ depends on the circumstance variables $C_{i}$, equation (1) is reduced to the stochastic relationship:

$$
W_{i}=C_{i}+u_{i}
$$

The dependent variable is a dummy variable, taking the value 1 if the respondent is employed and 0 otherwise. Thus, following the literature (e.g., Bourguignon, Ferreira,\& Menendez, 2007; Krafft\&Assaad, 2016), maximum likelihood method is used to estimate the following logit model, where the Xs represent the vector of circumstance variables $\left(C_{i}\right)$ in equation (2):

$$
\ln \left(\frac{P_{i\left(w_{i}=1 \mid x_{1} \ldots ., x_{k}\right)}}{1-P_{i}\left(w_{i}=1 \mid x_{1}, \ldots, x_{k}\right)}\right)=\beta_{0}+\beta_{1} X_{1}+\ldots \ldots \ldots+\beta_{k} X_{k}
$$

As we noted earlier, with equal opportunities, the circumstances should not matter, so that regression of equation (3) should have a bad fit; otherwise, circumstances affect the outcome significantly, and we will have inequality of opportunity. A weakness of this approach is that it provides only lower-bound estimates of inequality of opportunity. This is mainly because the part of inequality due to unobserved circumstances might be wrongly attributed to effort instead of to inequality of opportunity (Ramos \& Van de Gaer, 2012). However, it is also argued that the regression coefficients for circumstances capture both the direct and indirect effects of these circumstances on outcomes. For example, parents' level of education may affect an individual's skill and effort, which will affect his employment opportunity directly. Using the parameter estimates of equation (3) and the corresponding vector of circumstances, the probability $\left(\widehat{P}_{i}\right)$ that each respondent has access to work can easily be computed.

So far, we have been setting the stage for estimating inequality of opportunity. The focus has been on relating the outcome variable $\widehat{P}_{i}$ to the vector of circumstances $C$ beyond the control of the individuals. The result may be described by the expected conditional outcome $\vec{P}_{i}=E\left(P_{i} \mid C_{v}\right)$, which is based on the logit (or probit) regression model to estimate the conditional probability. This method, proposed by Paes de Barros et al. (2007), ensures scale invariance of the inequality of opportunity measure, but it is sensitive to translation. Thus, Soloaga and Juarez (2013) proposed a modified version that ensures translation invariance (both (Paes de Barros et al., 2007), and (Soloaga\& Juarez 2013) are cited in Florian and Isidro (2014).

Irrespective of the method of estimating (3), inequality of opportunity is then computed using a common absolute inequality measure, given by $\partial_{A}-I(\hat{\mathcal{P}})$. This index suggests that all variation in the vector $(P)$ is due to circumstances only; hence, it refers to inequality of opportunity. The appropriate inequality measure depends on the dependent variable. Paes de Barros et al. (2009) used the dissimilarity index, Ferreira and Gignoux (2011) used the mean logarithmic deviation, and Ferreira and Gignoux (2014) used the variance. Dividing the absolute inequality measured by the same index $I(P)$ applied to the actual outcome $P$ gives a relative measure of inequality of opportunity, given by $\theta_{B}=I(\hat{P}) / I(P)$. However, the calculation of this relative measure is possible only when the inequality measure is equally defined for $\widehat{P}_{i}$ and $\mathcal{P}_{t}$. This is not possible when the actual outcome is binary, while $\widehat{P}_{z}$ is the estimated probability. 
Having estimated the inequality of opportunity measure, we address an important policy question related to the extent of such inequality that is attributed to differences in circumstances. A number of methods can be used to address this issue. Once the predicted values of the dependent variable that are explained purely by circumstances at birth are calculated for each individual, the well- known Gini coefficient can then be calculated for the distribution of these predicted values.

However, with binary outcomes, a different measure of the extent of inequality of opportunity is required. A commonly used measure, in this case, is a "dissimilarity index" (D-index), defined as the average gap between predicted outcomes (probabilities) and the actual mean of outcomes. Higher (lower) predicted outcomes (probabilities) due to favorable (unfavorable) circumstances would lead to a higher (lower) D-index. A modified version of the D-index due to Paes de Barros et al. (2007) is used here and is given by:

$$
D^{*}=\frac{1}{2 P} \sum_{i=1}^{n} \theta_{i}|\hat{P} i-\bar{P}|
$$

Where (n) is the sample size, and $\bar{p}=\sum_{i=1}^{n} \theta_{i} P_{i}$, with $\epsilon_{i}=\frac{1}{3}$ or any other sampling weight.

As we mentioned earlier, equality of opportunity is achieved only if the distributions of the advantages are identical for all types. Based on the dissimilarity index, equality of opportunity will be achieved only if the probability of each individual accessing employment

$\left(\hat{P}_{i}\right)$ is equal to the average probability $\bar{P}$ for the entire population. The dissimilarity index

denoted $\mathrm{D}$, measures the difference between these two probabilities. The index takes values between 0 , meaning perfect equality, and 1 meaning perfect inequality (Peragine, 2011).

Another central issue for public policy is to assess how different sources of inequality in opportunity affect overall inequality. Thus, decomposing overall inequality according to the source (circumstances) helps in designing public policies to improve these circumstances and the resulting distribution of opportunities. The contribution of each circumstance to inequality of opportunity is captured by Shapley (1953) and Binder-Oaxaca decomposition methods (Blinder, 1973; Oaxaca, 1973).

The Shapley (1953) decomposition of inequality by factor components is adapted from cooperative game theory. According to this method, total inequality of opportunity can be broken down into shares attributable to each circumstance, with the shares adding up to one. To compute the Shapley decomposition, we first estimate the inequality measure for all possible permutations of the circumstance variables. Then, we compute the average marginal effect of each circumstance variable on the inequality of opportunity measure (Florian and Isidro, 2014). Shapley decomposition has substantial advantages over other methods; in that the decomposition is order independent, and the sum of different components equals the total value. Ferreira and Gignoux (2014) argued that this decomposition is not causal, but gives 
only an idea of the relative importance of each circumstance variable in total inequality. The reason is that most circumstances are highly correlated so that the estimated coefficients might suffer from multicollinearity. However, this multicollinearity is a problem for the decomposition but not for the point estimates of inequality of opportunity.

A second widely used method to analyze differences (gaps) in inequality of opportunity by groups is the Blinder-Oaxaca decomposition (Blinder, 1973; Oaxaca, 1973). To have inequality of opportunity, two conditions must be satisfied: people have to differ in the circumstances, and these circumstances must also affect inequality of opportunity. Therefore, differences in inequality of opportunity between groups can be attributed to differences in the circumstances or to differences in the impact of circumstances on the inequality of opportunity. The standard Blinder-Oaxaca decomposition technique allows one to identify the part of the difference that is due to different circumstances and the part that is due to differences in how the circumstances affect the inequality of opportunity. According to this decomposition method, inequality of opportunity is computed for each group individually. A counterfactual measure of inequality of opportunity is then computed for each group by computing inequality of opportunity of women, for example, using the circumstances of men (the estimated regression coefficients). All differences between the actual value for women, and this counterfactual measure are attributable to differences in the circumstances. Besides comparing two groups, the Blinder-Oaxaca method also allows analyzing the differences in one group for two different points in time. Identifying the sources of the differences between the two groups or two periods is crucial for policy design.

\section{Results and Discussion}

This paper employs data from the National Baseline Household Budget Survey (NBHBS) conducted in 2014 by the Central Bureau of Statistics with financial support from the African Development Bank. The survey aimed to provide a wide range of socioeconomic information to help inform economic and social programs in preparing the Poverty Reduction Strategy Paper for Sudan. It covers several fields, mainly: (i) household expenditure and consumption; (ii) food consumption; (iii) poverty and its determinants; and (iv) households' welfare.

The survey was designed to collect panel data from the sampled households at three points in time, namely November 2014, March 2015, and August 2015, with a view to capturing seasonal effects. The follow-up rounds administered only the consumption module. The 2008 Population Census represented the sample frame. A representative sample of size 13,800 households was drawn from all eighteen States of Sudan. By the end of the third round, the final sample of the survey consisted of 11,953 households. The sample used in this paper represents 50 percent of the final sample of the survey. The sampling information is available in the National Report released by the Central Bureau of Statistics.

For the purposes of this paper, we have used the survey data on employment, as well as on all circumstance variables on which data is reported in the survey, namely gender, mode of living, region of residence, and status of poverty. The variable "region" is re-coded from the 18 States, with Khartoum State used as a reference region. The remaining States were used to create five other regions by aggregating every two or more adjacent States into one region. Information on parents' education and occupation were not available. Therefore, these two 
variables were not included in the model.

The first step toward analyzing inequality of opportunity with regard to employment in Sudan is to estimate the logistic model in equation (3) and calculate the probabilities of accessing employment $\widehat{P}_{i}$. Table 1 reports the estimated coefficients, the p-values, and the odds ratio estimates from the logistic regression. Interpretations of the results are based on the odds ratios. According to the findings, the circumstance variables are jointly significant at the $1 \%$ level in determining the likelihood of employment. Females seem to be in a worse position to access employment compared to males. The odds of being employed versus unemployed are 84 percent lower for females compared to males, other variables remaining equal. The odds ratio estimated for the female dummy variable indicates the significance of gender as an important factor in accessing employment. This finding is consistent with those of previous studies such as Oloni (2015) for Nigeria and Nour (2011) for Sudan. Thus, the gender gap has persisted over time, reflecting a lack of dynamism in the labor market. In line with the Sustainable Development Goals, public policy should be geared toward women empowerment by eliminating the gender gap in employment.

Table 1. Results of logistic regression (with Employment as the Dependent Variable)

Indpt. Variables Coefficients (B) Standard errors P-value Odds ratios: E( $(\beta)$

Sex:

Male:

Reference

Reference

Reference

Female:

$-1.821$

0.0665

$0.000 \quad 0.1618$

Poverty status:

Poor:

Reference

Reference

Reference

Not poor:

0.064

0.0664

$0.334 \quad 1.066$

Mode of Living:

Urban:

Reference

Reference

Reference

Rural:

0.773

0.0667

0.000

2.166

Region of residence:

$\begin{array}{lllll}\text { Khartoum: } & \text { Reference } & \text { Reference } & & \text { Reference } \\ \text { Northern: } & 0.375 & 0.142 & 0.793 & 1.003 \\ \text { Eastern: } & 0.675 & 0.135 & 0.000 & 1.965 \\ \text { Central: } & 0.347 & 0.116 & 0.003 & 1.414 \\ \text { Kordufan: } & 0.614 & 0.118 & 0.000 & 1.849 \\ \text { Darfur: } & 0.726 & 0.112 & 0.000 & 2.067 \\ \text { Constant: } & 2.534 & 0.161 & 0.000 & \\ \text { No. of observations } & 8561 & & & \\ \text { LR } & 1091.8 & & & \end{array}$




\section{Prob. $>$ chi2 $\quad 0.0000$ \\ Pseudo $\mathbf{R}^{2}$ \\ 0.1374}

Source: Authors' calculations based on data from the NHBPS, 2014.

The odds of being employed versus being unemployed for the non-poor are 1.06 times that for those who are poor, implying that better-off people are also those who are more likely to be employed. Thus, it is the wealthy class that also stands better chances of accessing employment. This may suggest poverty perpetuation. Similar results were reported in the literature (e.g., British Geological Survey, 2010; Armah, Ekumahet al., 2018).

The odds of "mode of living" are also highly statistically significant. The odds of employment for rural areas are 2.21 times that for urban areas. According to the survey, 41 percent of people in rural areas are self-employed, compared to 24 percent in urban areas. This is consistent with the findings of McKinley and Draft (2001), who observed that in contrast to urban areas, the unemployed in rural areas (3.1 percent) were growing slower than the employed (4.2 percent). Rural-urban migration may also trigger urban unemployment through migration of rural surpluses to urban centers where the jobs available are not enough to absorb them.

The variable "regions of residence" represents the spatial segregation in employment probabilities. The odds of being employed versus being unemployed are higher for all regions compared to Khartoum State, and the results are highly significant, except for the Northern region. This may be attributed to internal migration in that region. According to the last population census, about 10 percent of the population changed their place of birth, and the majority moved to Khartoum State seeking a better life. However, the influxes of internal migrants, coupled with immigrants from neighboring countries into Khartoum State have led to severe competition for jobs in the face of few employment opportunities in Khartoum (except in informal-sector of trading and services), and the small share of the manufacturing sector in employment generation (McKinley \& Draft, 2001).

The data of the NHBPS of 2014 suggests that 18 percent of the labor force was unemployed. Two indices were used to measure inequality of opportunities in accessing employment. The first is due to Paes de Barros et al. (2009), while the second is proposed by Chávez-Juárez, and Soloaga (2015). The results suggest that dissimilarity in accessing employment due to inequality of opportunity varies between 7 percent using Paes de Barros et al. (2009), method and 23.0 percent using Chávez-Juárez, and Soloaga (2015) modified method. Although the index based on Paes de Barros et al. (2009), method is low, it is slightly above one-fifth of the modified index proposed by Chávez-Juárez, and Soloaga (2015). As we noted earlier, the relative dissimilarity index is not defined for a logit (or probit) model, where the dependent variable is binary.

Total inequality of opportunity was decomposed into its four circumstance variables, namely gender, mode of living, region of residence, and status of poverty. The results of Shapley decomposition in Table 2 suggest that gender scored the largest share (73.41 percent) in the inequality index, meaning that it represents the major source of the inequality of opportunity in accessing employment. Mode of living (20.37 percent) comes second in place, followed by 
region of residence (5.40 percent) and status of poverty ( 0.30 percent).

Table 2. Shapley decomposition of inequality of opportunity in the labor market in Sudan,2014

\begin{tabular}{lll}
\hline Variable & Value & Percentage (\%) \\
\hline Gender & 0.0511 & 73.41 \\
Mode of Living & 0.0142 & 20.37 \\
Residential regions & 0.0037 & 5.40 \\
Poverty status & 0.0002 & 0.30 \\
Total & $\mathbf{0 . 0 6 9 7}$ & $\mathbf{1 0 0 . 0 0}$ \\
\hline
\end{tabular}

Source: Authors' calculations based on data from the NHBPS, 2014.

Since gender appeared to be the primary source of inequality of opportunity in accessing employment, the Blinder-Oaxaca decomposition method was used to explore the sources of the differentials in such inequality in employment between males and females. Following this method, we first estimated two group-specific regressions and then performed the default three-fold decomposition, which is expressed from the view point of group 2 (females). The decomposition output in the first panel of Table 3 indicates that the average predicted probability of accessing employment is estimated at 0.865 for males and 0.591 for females, yielding a gap of 0.274 .

In the second part of Table 3, the gap in the probability of accessing employment is divided into three parts. Apart from circumstance variables, the first part suggests an average increase of 0.008 in the probability of women's access to employment, which measures the effect on the opportunity due to differences in the average characteristics (endowments) of the two groups, males and females. This difference accounts for 2.9 percent of the total difference in inequality of opportunity, indicating that females have slightly better characteristics (endowments), as reflected by the coefficient of endowment. The second part quantifies the change in women's opportunity when applying the men's coefficients to women's characteristics. The difference of 0.249 in the coefficients indicates that differences in the determinants of circumstances between the two groups account for 90.8 percent of the total difference in employment opportunity. However, it includes the effects of group differences in unobserved predictors. This is interpreted as discrimination against females. The third part is an interaction term to capture the simultaneous effect of differences in endowments and coefficients, which turned out to be insignificant. 
Table 3. Blinder-Oaxaca decomposition of inequality of opportunity in the labor market by gender

\section{Number of obs $=\mathbf{5 5 7 5}$}

$\begin{array}{ll}\text { 1:Male }=0 & \mathrm{n} 1=3943 \\ \text { 2:Female }=1 & \mathrm{n} 2=1632\end{array}$

Employment: Coefficients Standard errors P-values $95 \%$ Confidence Interval

\section{Differential}

$\begin{array}{llllll}\text { Male } & 0.865 & 0.0062 & 0.000 & 0.8537 & 0.8782 \\ \text { Female } & 0.591 & 0.0120 & 0.000 & 0.5681 & 0.6155 \\ \text { Difference } & 0.274 & 0.0136 & 0.000 & 0.2474 & 0.3008\end{array}$

\section{Decomposition}

\begin{tabular}{llllll} 
Endowments & 0.008 & 0.0049 & 0.094 & -0.0014 & 0.0180 \\
Coefficients & 0.249 & 0.0128 & 0.000 & 0.2247 & 0.2751 \\
Interaction & 0.015 & 0.0036 & 0.000 & 0.0087 & 0.0231 \\
\hline
\end{tabular}

Source: Authors' calculations based on data from the NHBPS, 2014.

\section{Conclusion}

Inequality of opportunity has placed itself at the heart of discussions on inequality and social welfare. It occurs when people living in a society do not enjoy the same opportunities. High levels of inequality of opportunity indicates that factors beyond the individuals' control, called circumstances at birth (e.g., their gender, mode of living, place of residence, or parental background) determine to a large extent their educational qualifications and employment opportunities and, ultimately, their level of earnings and welfare. Thus inequality of opportunity is widely regarded as an unfair part of inequality.

Despite the privatization efforts and the stringent measures toward a transition to a market economy in the early 1990s, the high expectations of greater and fairly distributed opportunities of employment for all have been partially aborted. A number of reasons might be cited in this respect, notably the armed conflicts, the cession of southern Sudan, and the loss of foreign exchange from oil exports, coupled with widespread corruption and the severe economic sanctions.

Dissimilarity in accessing employment due to inequality of opportunity caused by differences in circumstances at birth varies between 7 percent using Paes de Barros et al. (2009) method and 23.0 percent using Chávez-Juárez, and Soloagaa (2015) modified method. Of the various circumstances that explain the inequality of opportunity in Sudan, gender figured out as the strongest driver, playing a particularly important role in determining inequality of opportunity. Despite the tremendous expansion in higher education and the increase in the probability of obtaining a university degree among younger cohorts, particularly women, the odds of being employed versus unemployed are 84 percent lower for females compared to males, indicating 
the significance of gender as an important factor in accessing employment. This is attributed to the prevalence of high rates of unemployment for women. While the overall rate of unemployment is estimated at an average of 15 percent during 1990-2018, the rate for women stands at an average of 22.2 percent compared to 12.6 percent for males. Moreover, women participate less in the labor force in the presence of higher levels of inequality of opportunity. While the overall average rate of participation amounted to 49.2 during the period, this rate is considerably lower for females ( 25.0 percent) compared to males ( 73.7 percent). While the overall participation rate has trended downwards during 1990-2018, the fall in the rate for females has been noticeable since 1996 (Figure 2).

Mode of living has a smaller impact on inequality of opportunity than gender, accounting for an average of 19.2 percent of total inequality of opportunity. Public policy should take account of regional imbalances. Despite the considerable efforts made during the last three decades, the pattern of public investment still remains biased against rural areas. Public investment is centralized, with rural areas where poverty is concentrated, receiving significantly smaller shares of public investment than wealthier urban areas (Vélezet al., 2012). Balanced development between urban and rural areas, particularly in health and education services, may ultimately improve the chances of accessing the labor market and reduce inequality of opportunity, thereby making all places equally suitable to live in.

Creating jobs for vulnerable groups, namely the young and women, should receive particular attention. Young people face skills mismatches in the labor market, which results in extending the gap between graduation and work. Thus, public policy should focus on improving the quality of education and its relevance to the needs of the labor market. This might require the involvement of the private sector in developing skills standards to match market needs. Further, the provision of career advice to help young males and females decide on their educational choices to match their future job choices is of paramount importance. Also, women's participation in the labor market in Sudan is constrained by poor working conditions, rigid working hours, lack of childcare for working mothers, and lack of reliable transport to and from work.

Needless to mention, inequality of opportunity also has implications for people's support for market reforms. Depending on its sources, inequality of opportunity can either hinder or support core economic and political reforms. When inequality of opportunity stems from differences in effort, rather than individual circumstances such as gender or place of birth, reforms will be perceived as fair. Thus, this paper recommends that reforms should be implemented in ways that serve the interests of the marginalized groups. Public policies may need to specifically target access to education and employment by the disadvantaged social groups, thereby helping them to improve their chances of accessing employment. Further studies in inequality of opportunity in labor market that are based on surveys conducted mainly on labor market are also recommended. The main limitation of this study was that some important and related information such as parent's education and occupation were not available. The availability of such information would have added much to our findings, albeit the study is among the pioneer studies that analyzed the inequality of opportunity in the Sudanese labor market literature. 


\section{References}

Abras, A., Hoyos, A., \& Narayan, A. (2013). Inequality of opportunities in the labor market: evidence from life in transition surveys in Europe and Central Asia. IZA J Labor Develop, 2, 7. https://doi.org/10.1186/2193-9020-2-7

Alesina, A., \& Rodrik, D. (1994). Distributive politics and economic growth. The Quarterly Journal of Economics, 109(2), 465-490. https://doi.org/10.2307/2118470

Armah, F. A., \& Ekumah, B. (2018). Access to improved water and sanitation in sub-Saharan Africa in a quarter-century. Heliyon, 4(11), e00931. https://doi.org/10.1016/j.heliyon. 2018.e00931

Arneson, R. J. (1989). Equality and equal opportunity for welfare. Philosophical Studies, 56(1), 77-93. https://doi.org/10.1007/BF00646210

Blinder, A. S. (1973). Wage discrimination: Reduced form and structural estimates. Journal of Human Resources, 8, 436-455. https://doi.org/10.2307/144855

Bossert, W. (1995). Redistribution mechanisms based on individual characteristics. Mathematical Social Sciences, 29(1), 1-17. https://doi.org/10.1016/0165-4896(94)00760-6

Bourguignon, F., Ferreira, F. H., \& Menéndez, M. (2007). Inequality of opportunity in Brazil. Review of Income and Wealth, 53(4), 585-618. https://doi.org/10.1111/j.1475-4991.2007. 00247.x

Chávez-Juárez, F., \& Soloaga, I. (2015). Scale vs. Translation Invariant Measures of Inequality of Opportunity When the Outcome is Binary.

Checchi, D., \& Peragine, V. (2010). Inequality of opportunity in Italy. The Journal of Economic Inequality, 8, 429-450. https://doi.org/10.1007/s10888-009-9118-3

Cohen, G. A. (1989). On the currency of egalitarian justice. Ethics, 99, 906-44. https://doi.org/10.1086/293126

Dworkin, R. (1981). What is Equality? Part 2: Equality of Resources, Philosophy and Public Affairs, 10(3), 185-246.

Fallon, P. R. (1987). Labor markets in Sudan: their structure and implications for macroeconomic adjustment. The World Bank.

Ferreira, F. H., Gignoux, J., \& Aran, M. (2011). Measuring inequality of opportunity with imperfect data: the case of Turkey. The Journal of Economic Inequality, 9(4), 651-680. https://doi.org/10.1007/s10888-011-9169-0

Francisco, H. G., \& Ferreira, J. G. (2014). The Measurement of Educational Inequality: Achievement and Opportunity, The World Bank Economic Review, 28(2), 210-246. https://doi.org/10.1093/wber/lht004

Ferreira, F. H. G., Lakner, C., Lugo, M. A., \& Özler, B. (2014). Inequality of Opportunity and Economic Growth: A Cross-Country Analysis, IZADiscussion Papers, No. 8243, Institute for the Study of Labor (IZA), Bonn. https://doi.org/10.1596/1813-9450-6915

Fleurbaey, M., \& Peragine, V. (2013). Ex Ante Versus Ex Post Equality of Opportunity. Economica, 80(317), 118-130. https://doi.org/10.1111/j.1468-0335.2012.00941.x

Fleurbaey, M. (1994). On fair compensation. Theory and decision, 36(3), 277-307. 
https://doi.org/10.1007/BF01079932

Florian, W. C. J., \& Isidro, S. (201). iop: Estimating ex-ante inequality of opportunity. Stata Journal, 14(4), 830-846. https://doi.org/10.1177/1536867X1401400408

Krafft, C., \& Assaad, R. (2016). Inequality of opportunity in the labor market for higher education graduates in Egypt and Jordan. The Middle East Economies in Times of Transition, Springer. https://doi.org/10.1007/978-1-137-52977-0_6

Kuznets, S. (1955). Economic growth and income inequality. The American economic review, 45(1), 1-28.

Lefranc, A., Pistolesi, N., \& Trannoy, A. (2008). Inequality of opportunities vs. inequality of outcomes: Are Western societies all alike? Review of income and wealth, 54(4), 513-546. https://doi.org/10.1111/j.1475-4991.2008.00289.x

Lewis, W. A. (1954). Economic development with unlimited supplies of labor. The Manchester School, 22(2), 139-191. ttps://doi.org/10.1111/j.1467-9957.1954.tb00021.x

Marrero, G. A., \& Rodríguez, J. G. (2013). Inequality of opportunity and growth. Journal of Development Economics, 104, 107-122. https://doi.org/10.1016/j.jdeveco.2013.05.004

McKinley, T., \& Draft, F. (2001). Employment Generation and Poverty Reduction in Sudan. World, 38, 18.

Nour, S. S. O. M. (2011). Assessment of the gender gap in Sudan. UNU-MERIT, Working Paper, (2011-004). https://doi.org/10.2139/ssrn.1856543

Nyokangi, E. M. (2014). Measuring inequality of opportunity in South Africa. University of Cape Town.

Oaxaca, R. (1973). Male-female wage differentials in urban labor markets. International Economic Review, 14, 693-709. https://doi.org/10.2307/2525981

Oloni, E. F. (2015). Gender Inequalities and Employment in Nigeria.

Paes de Barros, Ricardo; Ferreira, F. H. G., Molinas, V., Jose, R., \& Saavedra, C. J. (2009). Measuring Inequality of Opportunities in Latin America and the Caribbean. Washington, DC: World Bank; New York: Palgrave Macmillan.

Peragine, V. (2011). Review of 'Measuring inequality of opportunities in Latin America and the Caribbean' by Ricardo Paes de Barros, Francisco H.G Ferreira, José R. Molinas Vega, and Jaime Saavedra Chanduvi, World Bank and Palgrave Macmillan. The Journal of Economic Inequality, 9(1), 137-143. https://doi.org/10.1007/s10888-010-9151-2

Ramos, X., \& Van de Gaer, D. (2012). Empirical approaches to inequality of opportunity: Principles, measures, and evidence.

Rawls, J. (1971). A Theory of Justice, Cambridge, MA: Belknap Press of Harvard University Press.

Roemer, J. E. (1998). Equality of Opportunity, Cambridge, MA: Harvard University Press.

Roemer, J. E., Aaberge, R., Colombino, U., Fritzell, J., Jenkins, S. P., Lefranc, A., .. San Segundo, M. J. (2003). To what extent do fiscal regimes equalize opportunities for income acquisition among citizens? Journal of Public Economics, 87(3-4), 539-65. https://doi.org/ 10.1016/S0047-2727(01)00145-1

Roemer, J. E., \& Trannoy, A. (2016). Equality of opportunity: Theory and measurement. 


\section{Macrothink}

Journal of Social Science Studies

ISSN 2329-9150

2020, Vol. 7, No. 2

Journal of Economic Literature, 54(4), 1288-1332. https://doi.org/10.1257/jel.20151206

Sen, A. (1980). Equality of What? The Tanner Lecture on Human Values, I, 197-220. Cambridge: Cambridge University Press.

Shapley, L. S. (1953). A Value for N-Person Game. In H. W. Kuhn, \& A. W. Tucker (Eds.), Annals of Mathematics Studies, 28, 307-317, Princeton University Press, Contributions to the Theory of Games. https://doi.org/10.1515/9781400881970-018

Van De Gaer, D. F. G. (1995). Equality of opportunity and investment in human capital.

Vélez, C. E., Al-Shawarby, S., \& El-Laithy, H. (2012). Equality of opportunity for children in Egypt, 2000-2009: achievements and challenges, The World Bank. https://doi.org/10.1596/ 1813-9450-6159

\section{Glossary}
1. Abbreviation
2. Description
3. NHBPS
4. National Household Budget and Poverty Survey
5. HOI
6. Human Opportunity Index

\section{Copyright Disclaimer}

Copyright for this article is retained by the author(s), with first publication rights granted to the journal.

This is an open-access article distributed under the terms and conditions of the Creative Commons Attribution license (http://creativecommons.org/licenses/by/3.0/). 